\title{
A comparison of automated static dark stimuli with the Humphrey STATPAC program in glaucomatous visual field loss
}

\author{
Erkan Mutlukan
}

\begin{abstract}
Visual field examination is conventionally performed with bright stimuli on a dark background. Dark stimuli on a bright background, however, may provide different information as light increases and decreases are subject to parallel processing in the visual pathway. Twenty five eyes with primary open angle glaucoma and visual field loss were examined with the Humphrey visual field analyser thresholding program $30-2$ and the computer assisted moving eye campimeter (CAMEC) using static dark stimuli at four different Weber contrast levels of $-10(n=9),-22$ $(n=25),-37(n=14)$, and $-76 \%(n=25)$ on a cathode ray tube with a background luminance of $10 \mathrm{~cd} / \mathrm{m}^{2}$. The cumulative results obtained with STATPAC 'pattern deviation' empirical probability maps and the results from each contrast of the dark stimulus at identical test locations were compared at eccentricity annuli bands of 4-9, 10-20, and 21-28 degrees. Dark stimuli of lower contrast provided higher abnormal point detection rates. Furthermore, visual field defects to the low contrast dark stimuli were more extensive than those to the luminous stimuli. In conclusion, dark stimuli allowed the delineation between glaucomatous field defects and the normal regions in the central visual field.
\end{abstract}

(Br F Ophthalmol 1994; 78: 175-184)

Visual field examination is universally performed with luminous stimuli on a relatively dim background. However, the visual system is thought to have differential sensitivity to both increases and decreases in light intensity as the end result of parallel processing in 'on' and 'off pathways respectively. These pathways start at the bipolar cell layer ${ }^{1}$ and project to central visual structures through the on centre and off centre retinal ganglion cells ${ }^{2-7}$ to provide a maximum contrast sensitivity function. ${ }^{89}$ 'On' and 'off' pathways display several morphophysiological, ${ }^{10-18}$ psychophysical, ${ }^{19-23}$ and electrophysiological asymmetries. ${ }^{24} 25$ The smaller number of off centre retinal ganglion cells ${ }^{4112627}$ suggests a smaller functional reserve (photoreceptor ganglion cell cortical neuron channels) in the visual system. Low contrast dark stimuli on low photopic and mesopic backgrounds may have higher affinity to the magnocellular system $^{28}$ which processes achromatic contrast..$^{30-33}$ As the magnocellular system is more vulnerable to glaucomatous neuronal damage, ${ }^{34-36}$ visual field examination with dark (negative contrast) stimuli may provide information which cannot be obtained using light stimuli. ${ }^{37} 38$

The high contrast black stimulus has previously been used for blind spot detection and fixation monitoring on a hand held tangent screen test chart. ${ }^{39}$ The black stimuli may reveal glaucomatous visual field abnormalities. ${ }^{40}$ The low, intermediate, and high contrast kinetic dark stimuli have been experimented with on a white Bjerrum screen in the diagnosis of cone dysfunction. ${ }^{41}$ The oculokinetic perimetry chart has also been described with a black stimulus. ${ }^{42}$ Multiple dark (negative contrast) stimuli on a tangent screen have been further developed in screening for neurological and glaucomatous visual field defects. ${ }^{43}$ Suprathreshold testing with kinetic black stimulus ${ }^{44}$ and, 'delay campimetry'46 which involves the recording of patient reaction times to static black stimuli at a number of locations in the visual field are known to yield additional clinical information especially in retinal inflammatory disorders and retrobulbar neuritis, respectively. However, computerised suprathreshold and threshold testing with low contrast static dark stimuli have not been reported until recently. ${ }^{47} 48$

In this study, static dark perimetric stimuli of varying contrast on a cathode ray tube are compared with conventional light stimuli of the Humphrey visual field analyser in glaucomatous eyes, using the STATPAC empirical probability maps as the standard.

\section{Materials and methods}

Twenty five glaucomatous eyes (17 right and eight left) of 25 perimetrically experienced patients with primary open angle glaucoma

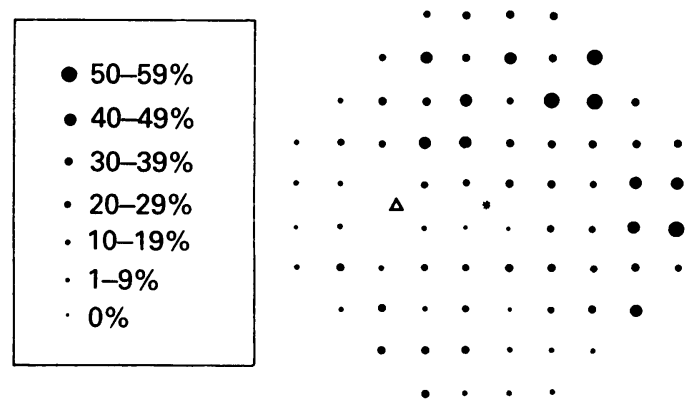

Figure 1 The cumulative frequency distribution of abnormal points in the central visual fields of 25 glaucomatous eyes according to the Humphrey autoperimeter STATPAC 'pattern deviation' results. All significant deviations from the normal (outside $95 \%$ confidence interval) constitute the abnormal (outside $95 \%$ confidence interval)
points with decreased sensitivity. 


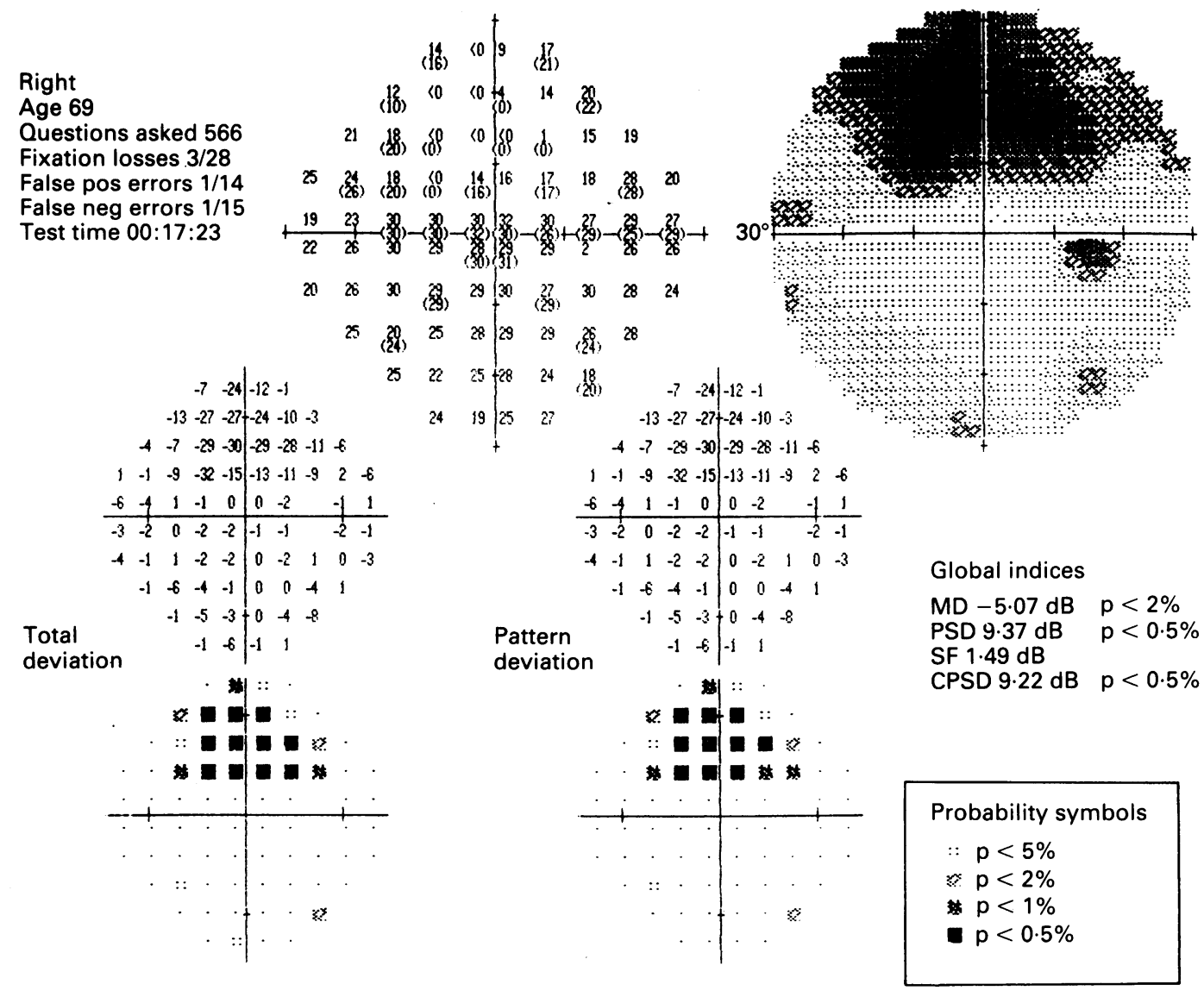

Greytone symbols

Fig $2 A$

Figure 2 The glaucomatous field loss in the superior Bjerrum area was evident to both $(A)$ conventional threshold light stimuli and $(B)$ all four contrasts of single intensity suprathreshold dark stimuli in the right eye of this 69-year-old woman. Interestingly, a subtle inferonasal defect became more pronounced with the lower contrasts (lighter grey) of the CAMEC stimuli.

(POAG) (13 male and 12 female), aged between 35-82 years (mean 68 years) were included in the study. All eyes had $6 / 6, \mathrm{~N} 5$, or better visual acuity with correction less than $\pm 7 \cdot 00$ dioptres spherical equivalent, no media opacities, and normal $(3-6 \mathrm{~mm})$ pupils. None of the patients suffered from non-glaucomatous ocular disorders or systemic disease.

The conventional perimetry was performed using the Humphrey visual field analyser program 30-2 with Goldmann stimulus size III $\left(4 \mathrm{~mm}^{2}\right)$ and a stimulus duration of 0.2 seconds. The patients were also tested with the computer assisted moving eye campimeter (CAMEC) which employs a moving fixation technique.99 The CAMEC technique requires an IBM compatible desktop computer with a joystick or mouse and a high resolution monitor. Static stimuli are presented automatically in relation to a randomly moving fixation target at predetermined locations in the central visual field. The patient signals awareness of the stimulus by pressing a button. Missed stimuli are presented a second time and repeatable misses are recorded as abnormal points in the visual field. Patient responses are processed, analysed, printed, and saved at the end of the test. The full details of computer assisted moving eye fixation are described elsewhere (Damato B E, et al, in press). The test grid designed for this study was identical to the test grid of Humphrey program 30-2. The CAMEC stimulus size was compensated for eccentricity, with a surface area of $1.8 \mathrm{~mm}^{2}$ up to 10 degrees, $3 \cdot 1 \mathrm{~mm}^{2}$ between 10 and 20 degrees, and $4.9 \mathrm{~mm}^{2}$ beyond 20 degrees from fixation. These sizes of dark stimuli, in a pilot study with 10 normal subjects, were detectable along the nasal horizontal meridian of the normal visual 


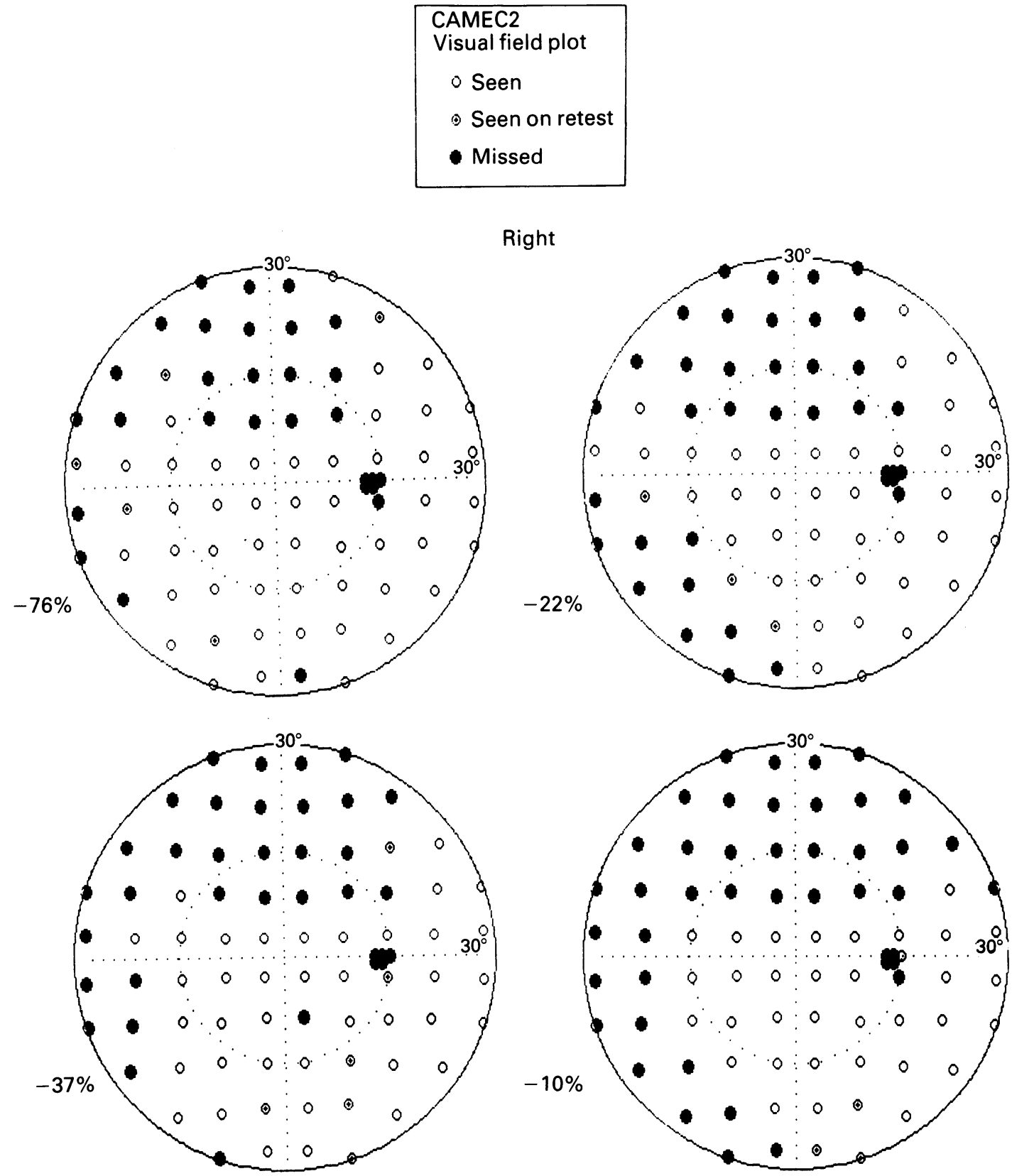

Fig $2 B$

field (Mutlukan, unpublished data). The static dark stimuli were presented for the default duration of 0.2 seconds. For calibration, the luminances of the test stimuli and background were measured at 36 different locations using a luminance meter (Minolta nt-1) and average luminance (Weber's) contrasts $\left(\mathrm{C}_{\mathrm{w}}\right)$ calculated. ${ }^{50}$ s1 Dark stimulus contrasts of $-76 \%$ (2 $\mathrm{dB}=20 \log \mathrm{C}_{\mathrm{W}}$; the darkest grey), $-37 \%$ (9 dB), $-22 \%(13 \mathrm{~dB})$, and $-10 \%(20 \mathrm{~dB}$, the lightest grey) were the only suitable grey tones of the EGA graphics software of CAMEC in giving a useful stimulus range. These dark stimulus contrasts were presented on a $10 \mathrm{~cd} / \mathrm{m}^{2}$ background. Tests were performed with single intensity stimuli as separate examinations in a random order either before or after the Humphrey 30-2 threshold test. All patients had prior demonstration/training for 1.5 minutes which involved the recognition of the dark stimuli for each test. The CAMEC (each) and Humphrey tests took an additional average of 10 and 15 minutes to complete, respectively. Patient fatigue was minimised by a few minutes of rest after each test session. All tests for each individual were performed with full aperture near correction at a $30 \mathrm{~cm}$ test distance and completed on the same day.

The Humphrey STATPAC 'empirical probability (p) values' as well as the dark stimulus detection status ('seen' or 'missed') for each contrast at the corresponding test locations were 
Right

Age 71

Questions asked 502

Fixation losses 6/26

False pos errors $0 / 12$

False neg errors $3 / 22$

Test time 00:14:40
$1728 t_{21}^{21} 17$

(3) $21 \quad 21 \quad 26 \quad 22 \quad 22$

(2i) $\left.23\right|^{24} \quad$ (21) $23 \quad$ (23)

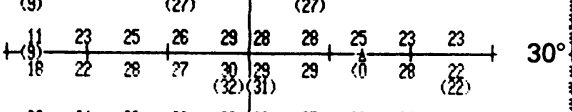

22

2

\begin{tabular}{ll|ll}
-5 & -5 & 1 & -3
\end{tabular}

$\begin{array}{lllllll}-13 & -4 & -4 & -2 & -2 & -1\end{array}$

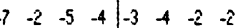

\begin{tabular}{lllll|lllll}
-12 & -4 & -4 & -2 & -2 & -1 & -2 & 3 & 0 & 1
\end{tabular}

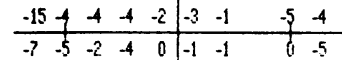

\begin{tabular}{lllll|lllll}
-2 & -3 & -7 & -2 & -1 & -4 & -3 & -1 & 0 & -1
\end{tabular}

\begin{tabular}{llll|llll}
-3 & 8 & 8 & -3 & 0 & -4 & -1 & -7
\end{tabular}

$\begin{array}{llllllllllll}-1 & -7 & 0 & 0 & 0 & -2 & -1\end{array}$

Total \begin{tabular}{ll|ll}
0 & -2 & 1 & -3
\end{tabular}

deviation

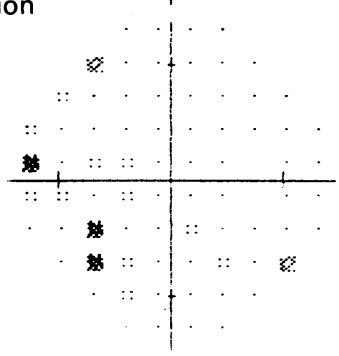

\begin{tabular}{ccc|cccc}
22 & 29 & 29 & 26 & 23 & 28 & 28 \\
25 & 20 & 27 & 28 & 26 & 26 &
\end{tabular}

$24 \quad 23 \quad 27 \quad 23$

26

26

(x)

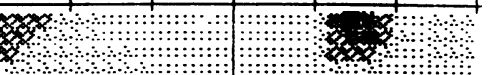

$\begin{array}{llllllllllll}-13 & -4 & -4 & +2 & -2 & -1\end{array}$

$\begin{array}{lllllllll}-7 & -2 & -5 & -4 & -3 & -4 & -2 & -2\end{array}$

\begin{tabular}{lllll|lllll}
-11 & -4 & -4 & -2 & -2 & -1 & -2 & 3 & 0 & 1
\end{tabular}

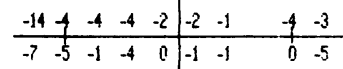

\begin{tabular}{lllll|lllll}
-2 & -3 & -7 & -2 & -1 & -4 & -3 & 0 & 0 & -1
\end{tabular}

\begin{tabular}{llll|llll}
-2 & 8 & -5 & -3 & 0 & -4 & -1 & -7
\end{tabular}

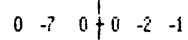

Pattern \begin{tabular}{ll|ll}
0 & -2 & 1 & -3
\end{tabular}

Global indices

MD $-2.87 \mathrm{~dB} \quad \mathrm{p}<10 \%$

PSD $3.00 \mathrm{~dB}$

SF $1.76 \mathrm{~dB}$

deviation

CPSD $2 \cdot 24 \mathrm{~dB}$

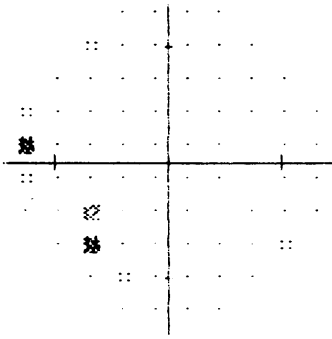

Probability symbols

$\therefore p<5 \%$

$\approx p<2 \%$

* $p<1 \%$

$p<0.5 \%$

Greytone symbols

Fig $3 A$

Figure 3 (A) The nasal field loss to the light stimuli of the Humphrey thresholding program appeared more extensive when compared with $(B)$ the lowest contrast $(-10 \%)$ dark stimuli, which also revealed double arcuate scotomas.

compared at eccentricity annuli bands of 4-9 degrees, 10-20 degrees, and 20-28 degrees using the 'Minitab' statistical software package. The sensitivity and specificity of the different dark stimulus contrasts were studied by performing point by point comparisons between the Humphrey 'total deviation' (TD), 'pattern deviation' (PD) plots, and CAMEC results, except the test locations above and below the physiological blind spot. The threshold results showing significant depression in 'TD' and 'PD' plots beyond $95 \%$ confidence interval (shown with STATPAC symbols representing p $<5 \%, 2 \%$, $1 \%$, and $0.5 \%$ ) were categorised as representing the visual field abnormality, and the remaining locations (inside $95 \%$ confidence interval, $\mathrm{p}>5 \%$ ) were considered healthy parts of the visual field. ${ }^{52}$ The TD result of STATPAC indicated the areas with both homogeneous and localised reduction in sensitivity, whereas the PD result showed only the localised component of any field defect. ${ }^{52}$

\section{Results}

STATPAC evaluation of the decibel threshold values revealed relative scotomas in 11 eyes (Aulhorn-Karmeyer classification, stage 1), small isolated absolute scotomas in 10 eyes (stage 2) and absolute scotomas connected to the blind spot in four eyes (stage 3 ) with the mean global visual field indices of $-5 \cdot 2 \mathrm{~dB}$ mean defect (MD); 6 $1 \mathrm{~dB}$ pattern standard deviation (PSD); $5.4 \mathrm{~dB}$ corrected pattern standard deviation (CPSD); and $2 \cdot 2 \mathrm{~dB}$ short term fluctuation (STF). ${ }^{534}$ The reliability indices from all Humphrey threshold results were within the normal range (that is, fixation losses $<20 \%$, false 


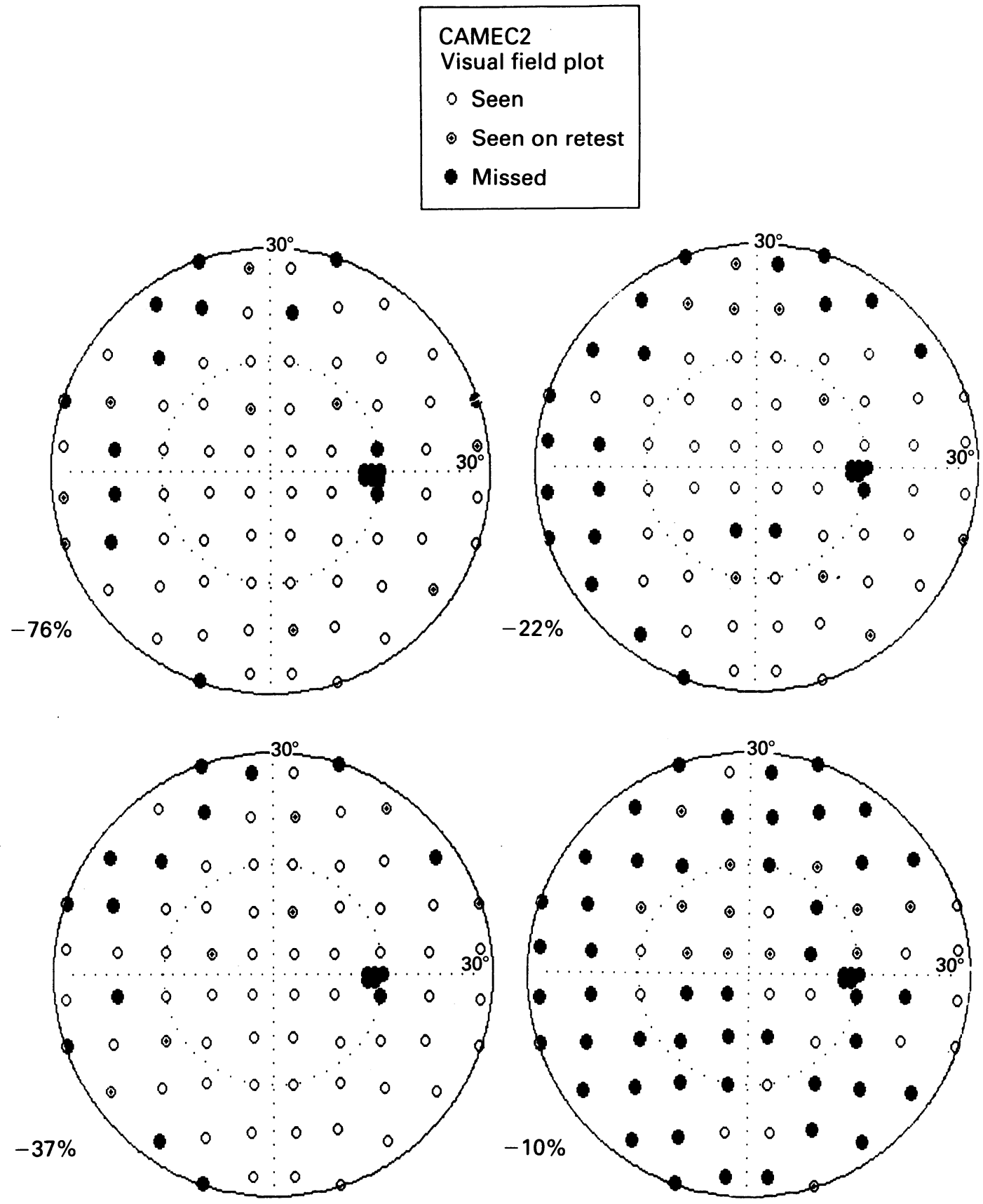

Fig $3 B$

answers $<33 \%$ of total attempts). The cumulative frequency of involvement of the test locations in the PD plots is shown in Figure 1.

All four contrasts of static dark stimuli indicated the abnormal areas in the central visual fields of glaucomatous eyes (Fig 2). In general, lower contrasts of dark stimuli delineated more extensive visual field abnormalities, and displayed abnormal areas which were not detected by the light stimulus and STATPAC (Fig 3). The highest contrast $(-76 \%$, black) stimuli and the lowest contrast $(-10 \%$, light grey) stimuli identified the normal and abnormal points respectively with the best accuracy at all eccentricity bands (Fig 4). For instance, the black
( $-76 \%$ contrast) stimulus identified $93 \%$ of the normal locations (true negative rate $=$ specificity) in PD plots as such with a false positive rate of $7 \%$ within 10 degrees from fixation; however, its true positive rate (detection of abnormality= sensitivity) for glaucomatous loss was only $49 \%$ in the same area. Both the true and false positive rates increased with increase in eccentricity. The true positive rate improved with lowering dark stimulus contrast and reached $86 \%$ at $-10 \%$ contrast with a higher 'false positive' rate of $35 \%$ within 10 degree eccentricity. That relation between the dark stimulus contrast and the detection rates was evident at all eccentricities. The average true and false positive detection 


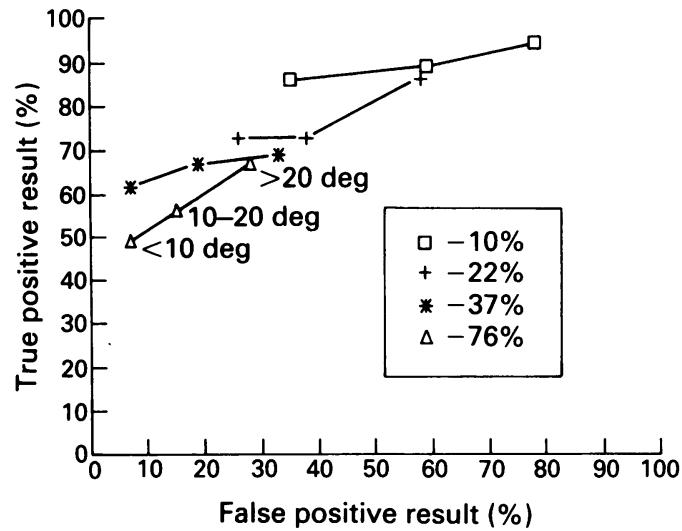

Figure 4 The percentage sensitivity (true positive result rate) and specificity (true negative result rate $=1-$ false positive rate) of the dark perimetric stimuli of varying contrast against STATPAC pattern deviation results at eccentricity annuli bands of 4-9 degrees, 10-20 degrees, and beyond 20 degrees within the glaucomatous central visual field at 4741 test locations.

rates obtained against the PD plots within the whole central field were higher than those against the TD results.

\section{Discussion}

At present, automated thresholding perimetry with light stimulus is the most sophisticated approach. It has the best sensitivity and specificity available especially in experienced patients. Indeed, the Humphrey visual field analyser with STATPAC has a wide acceptance for the standardised evaluation of glaucomatous patients. STATPAC automatically compares the measured light threshold decibel (dB) values with the age-expected normal $\mathrm{dB}$ values and indicates the deviations from normal. STATPAC considers a given $\mathrm{dB}$ light sensitivity value abnormal (outside $95 \%$ confidence interval) if that value is $5 \mathrm{~dB}$ or lower than the expected sensitivity. It enabled the identification and classification of the normal and abnormal areas in the glaucomatous visual fields according to their defect depth and level of statistical significance. ${ }^{5 s}$ The 'total deviation' plot reflects not only the localised defects but also the effect of inappropriate refractive correction, pupil size, and media opacity on visual sensitivity as well as the generalised loss component of glaucomatous visual field involvement. The concept of a generalised (diffuse, homogeneous) sensitivity loss component in glaucoma still remains controversial although it was reported to be present in nearly half of the eyes with glaucomatous visual field involvement. ${ }^{56-58}$ The frequency of visual field abnormality in the TD plots from the eyes included in this study were significantly higher than that in the PD plots $(p<0.001)$. This finding suggests the presence of glaucomatous diffuse sensitivity loss in these eyes since the field artefacts which may have been caused by preretinal factors were minimised by careful selection of the patients (Mutlukan and Jay, in preparation). Slightly higher (an average of 3-6\%) false positive rates against the $\mathrm{PD}$ results suggest that the detection of the dark stimuli, like the light stimuli, is influenced by the diffuse sensitivity loss in the visual field.

It was previously demonstrated that the visibility of the dark perimetric stimulus is dependent on stimulus parameters such as stimulus size, contrast, and level of background luminance. ${ }^{59}$ Accordingly, eccentricity compensated sizes of dark stimuli follow the slope of the normal hill of vision at all contrast levels, with the lower contrast levels requiring higher retinal sensitivity for their detection. The results from this study further confirm that, similar to the conventional incremental threshold examination, the decremental differential sensitivity in the visual field can be determined and the abnormalities can be quantified with successive presentations of different dark stimulus contrasts in increasing or decreasing steps. ${ }^{47}$

Dark stimuli of low contrast were frequently missed in apparently normal parts of the glaucomatous visual fields, especially at the outer eccentricities. This is partly due to the negative effect of the peripheral stimuli locations on patient attentiveness ${ }^{60}$ as well as the possible

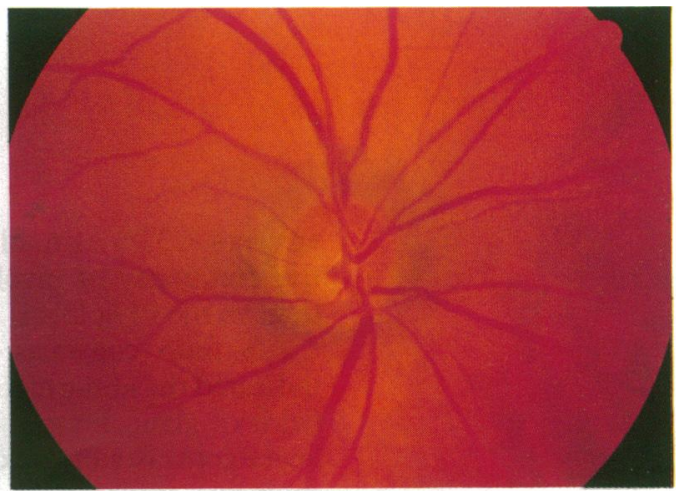

Fig 5 A right 

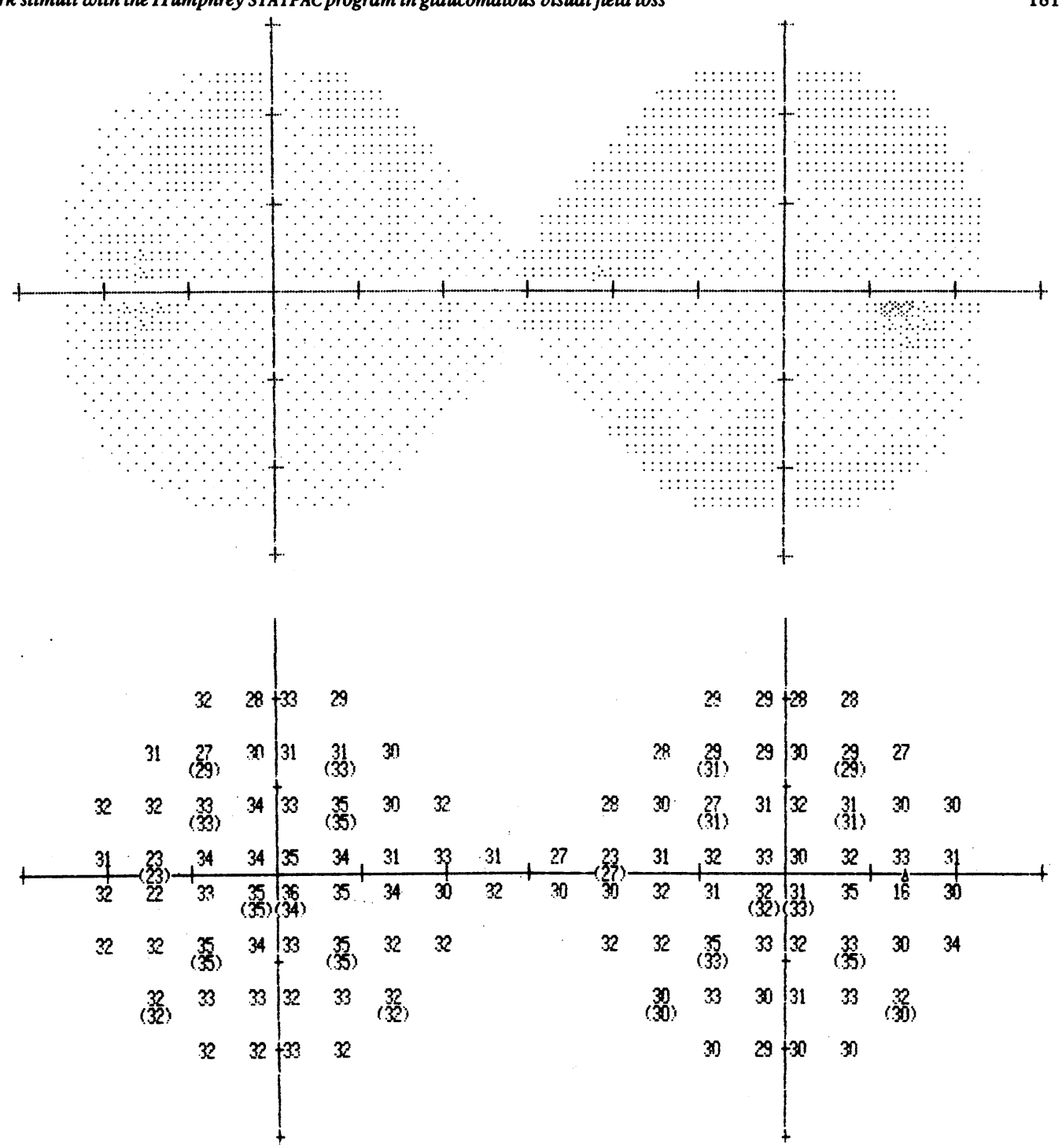

Figure 5B Conventional automated threshold stimulus

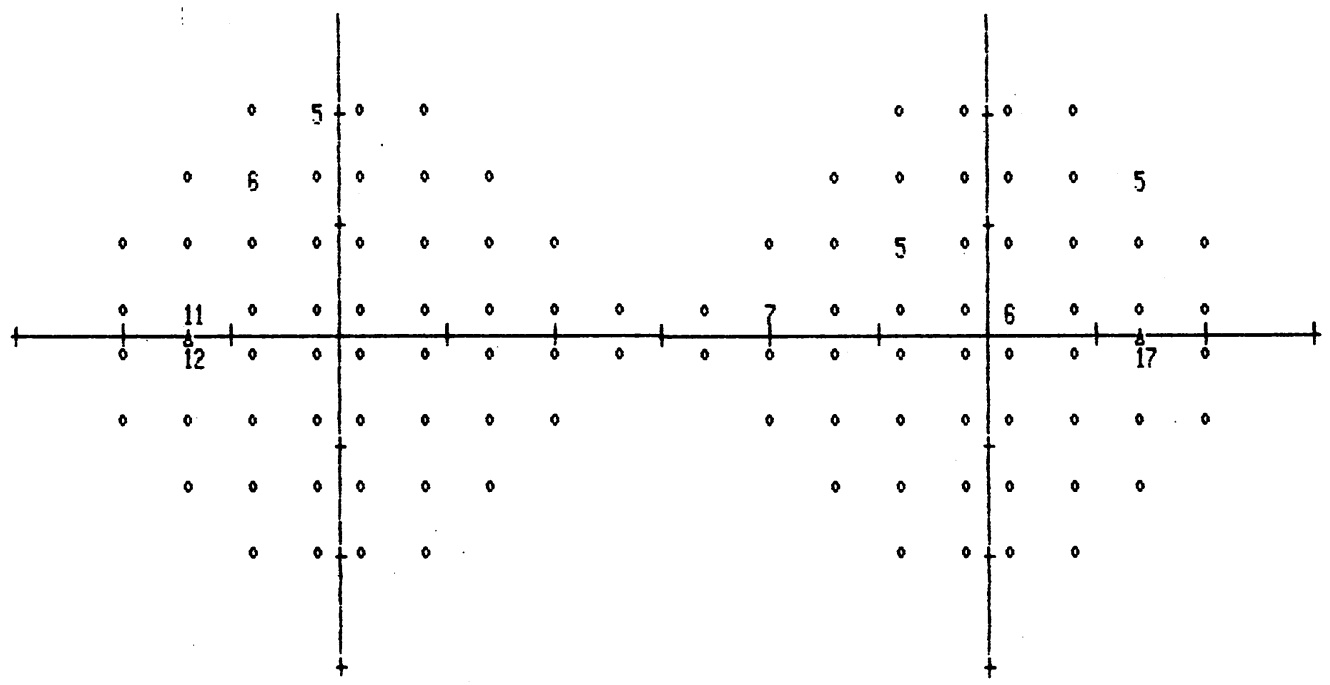

Greytone symbols

Rev 5.3

\begin{tabular}{|c|c|c|c|c|c|c|c|c|c|c|}
\hline Sym & & & & 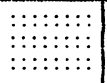 & का को & ४ै\% & 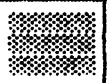 & 索 & 8 & \\
\hline Asb & .9 & $2_{i} 5$ & $\theta_{t z}$ & 25 & $\begin{array}{r}79 \\
92\end{array}$ & $\begin{array}{c}251 \\
100\end{array}$ & $\begin{array}{r}794 \\
310\end{array}$ & $\begin{array}{l}2512 \\
1000\end{array}$ & $\begin{array}{l}7943 \\
3192\end{array}$ & $\frac{7}{100010}$ \\
\hline & $50^{41}$ & ${ }_{40}=$ & $35^{31}$ & 20 & 25 & $2=$ & $15^{11}$ & $10^{E}$ & $5^{t-1}$ & $\leqslant 0$ \\
\hline
\end{tabular}


Figure 5C Threshold determination with equal size and duration of static dark stimuli revealed field loss in the right eye.

\section{CAMEC22 Visual field plot}

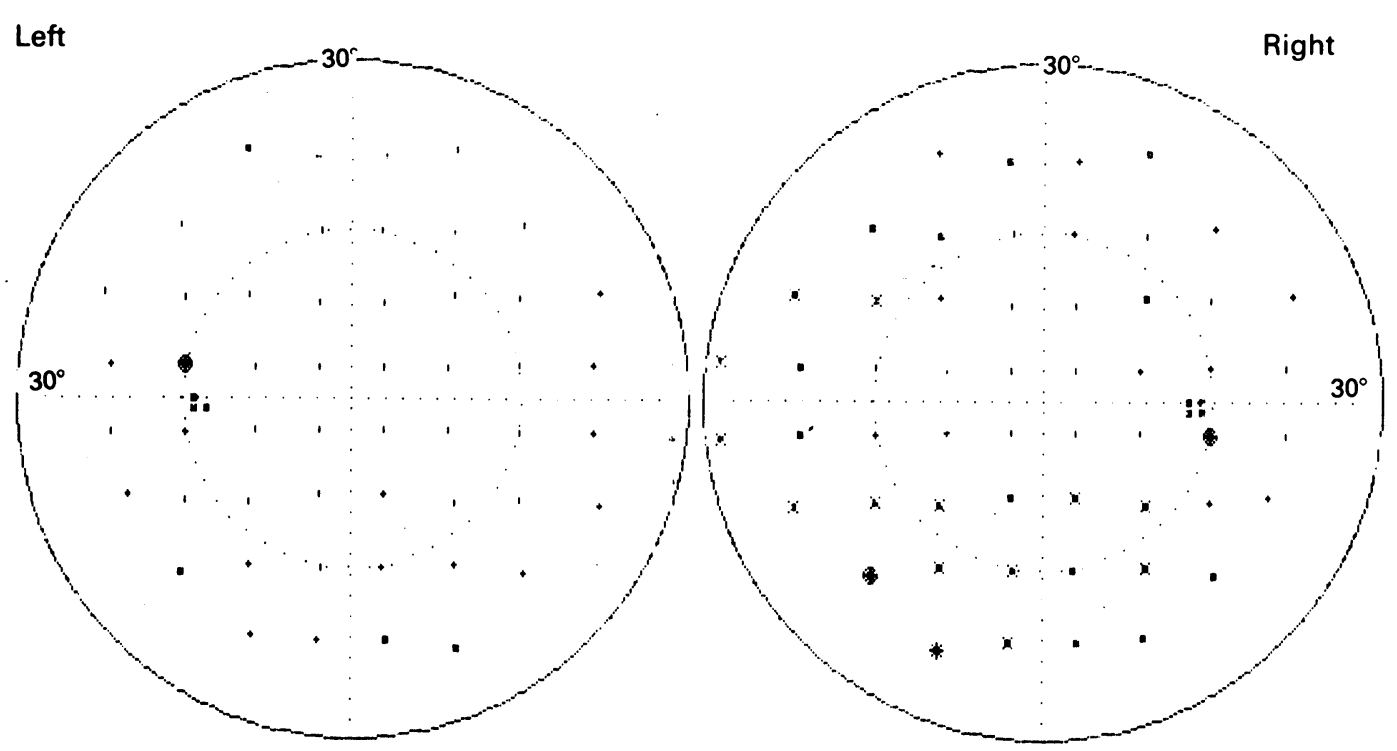

Left

Right

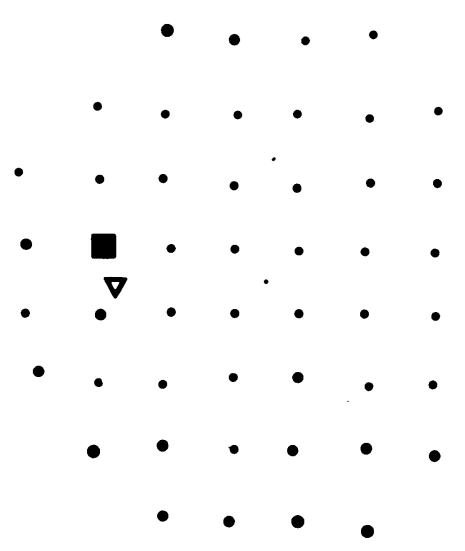

$13 \mathrm{~dB}$

- $15 \mathrm{~dB}$

- $17 \mathrm{~dB}$

- $19 \mathrm{~dB}$

- $23 \mathrm{~dB}$

Left eye

Figure 5D The total sensitivity to the dark stimuli in the glaucomatous right eye was $152 \mathrm{~dB}$ less than that in the fellow eye $(0 \mathrm{~dB}=$ $-100 \%$ contrast, black stimulus).

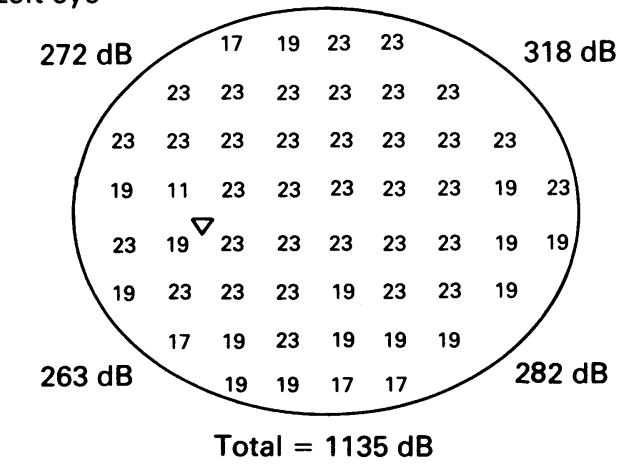




\begin{tabular}{|c|c|c|c|c|c|c|c|c|}
\hline & & & $16 \cdot 0$ & 16.0 & 15.5 & $13 \cdot 6$ & & \\
\hline & & $17 \cdot 1$ & $18 \cdot 7$ & $18 \cdot 3$ & $19 \cdot 3$ & $16 \cdot 9$ & $16 \cdot 6$ & \\
\hline & $15 \cdot 6$ & $18 \cdot 7$ & $20 \cdot 2$ & $20 \cdot 2$ & $20 \cdot 2$ & 18.7 & $19 \cdot 3$ & $16 \cdot 6$ \\
\hline 14.3 & $16 \cdot 6$ & $19 \cdot 3$ & 22.0 & 22.0 & $22 \cdot 0$ & 22.0 & * & $18 \cdot 3$ \\
\hline \multirow[t]{4}{*}{$15 \cdot 2$} & $17 \cdot 1$ & $22 \cdot 0$ & 22.0 & $22 \cdot 0$ & $22 \cdot 0$ & 22.0 & * & 16.9 \\
\hline & $16 \cdot 0$ & $18 \cdot 2$ & $17 \cdot 8$ & 20.2 & $19 \cdot 3$ & $18 \cdot 7$ & $18 \cdot 3$ & $16 \cdot 1$ \\
\hline & & 15.5 & $17 \cdot 4$ & $16 \cdot 1$ & $17 \cdot 7$ & 16.5 & $16 \cdot 1$ & \\
\hline & & & 13.7 & 16.0 & $16 \cdot 0$ & $16 \cdot 1$ & & \\
\hline
\end{tabular}

Figure 5E Minimum age-expected normal dark stimulus threshold values for 60 years of age in the central visual field (95\% confidence interval $=$ mean $-2 S D$ for each test location; $n=13$ ).

decrease in the suprathreshold values of the selected dark stimulus sizes in glaucomatous visual fields. The true negative rate of $71 \%$ from the lightest grey $(-10 \%)$ dark stimuli within 10 degree eccentricity provides evidence that even the lowest negative contrast value employed in this study was at least $4 \mathrm{~dB}$ above the equivalent light threshold in the central visual field. Therefore, seemingly false positive results from dark stimuli also suggest that negative contrast was detecting early glaucomatous visual field defects which were being missed with the luminous (positive contrast) stimuli of the Humphrey visual field analyser. Glaucoma is known to selectively damage retinal ganglion cells with large somal diameter ${ }^{34-36}$ and off centre ganglion cells are included in that morphological category. ${ }^{3}$ The results from threshold examination with static dark on bright stimuli in glaucoma suspect eyes further support the concept that the dark stimuli may diagnose visual field abnormalities before they become evident to equal sizes and durations of conventional positive contrast stimuli (Fig 5).$^{61}$

The differential involvement of the 'off' pathway in glaucoma and other neuro-ophthalmic disease, the affinity of the dark stimuli to the magnocellular system, and the diagnostic advantage of performing threshold determination with dark on bright stimuli require further clinical trials.

This study was conducted at Tennant Institute of Ophthalmology, University of Glasgow, Scotland.

The author was supported financially by The Internationa Glaucoma Association, The Royal National Institute for the Blind, The Ross Foundation of Prevention of Blindness, and McCunn Trust, and wishes to thank Dr B E Damato for his review of the earlier version of this manuscript, Mr J McGarvie and Dr A Evans for the software improvements, Drs Jay, Dutton, Dudgeon, Cant, Bronte-Stewart, McFadzean, and Professor Kirkness for their kind permission to examine their patients.
1 Saito T. Physiological and morphological differences between on- and off-center bipolar cells in the vertebrate retina. Vision Res 1987; 27: 135-42.

2 Wagner HG, MacNichol EF, Wolbarsht ML. Functional basis for 'on-center' and 'off-center' receptive fields in the retina. F Opt Soc Am 1963; 53: 66-70.

3 Famiglietti EV, Kolb H. Structural basis for on and off center responses in retinal ganglion cells. Science $1976 ; 194$ : 193-5.

4 de Monasterio FM, Gouras P. Functional properties ganglion cells of the rhesus monkey retina. F Physiol 1975; 251: 167-95.

5 Schiller PH. Central connections of the retinal on and off pathways. Nature 1982; 297: 580-3.

6 Schiller PH. The connections of the retinal on and off pathways to the lateral geniculate nucleus of the monkey. Vision Res 1984; 24: 923-32.

7 Miller KD. Development of orientation columns via competition between on- and off-center inputs. Neuroreport 1992; 3 $73-6$.

8 Schiller PH, Sandell JH, Maunsell JH. Functions of the ON and OFF channels of the visual system. Nature 1986; 322 ; 824-5.

9 Schiller PH. The central visual system. Vision Res 1986; 26: 1351-88.

10 Perry VH, Silveira LC. Functional lamination in the ganglion cell layer of the macaque's retina. Neuroscience 1988; 25 : cell layer

11 de Monasterio FM. Asymmetry of on and off pathways of blue sensitive cones of the retina of macaques. Brain Res 1979; 166: 39-49.

12 Malpeli J, Schiller P. Lack of blue off-center cells in the visual system of the monkey. Brain Res 1978; 141: 385-9.

13 Schiller PH, Colby CL. The response of single cells in the lateral geniculate nucleus (LGN) of the rhesus monkey to colour and luminance contrast. Vision Res 1983; 23: 163141.

14 Schiller PH, Malpeli JG. Functional specificity of lateral geniculate nucleus laminae of the rhesus monkey. 7 Neurogeniculate nucleus laminae
physiol 1978; 41: 788-97.

15 Kageyama GH, Wong Riley MT. The histochemical localization of cytochrome oxidase in the retina and lateral geniculate nucleus of the ferret, cat, and monkey, with geniculate nucleus of the ferret, cat, and monkey, with particular reference to retinal mosaics and ON
visual channels. F Neurosci $1984 ; 4: 2445-59$.

16 Liu S, Wong Riley M. Quantitative light- and electronmicroscopic analysis of cytochrome-oxidase distribution in neurons of the lateral geniculate nucleus of the adul monkey. Vis Neurosci 1990; 4: 269-87.

17 Schiller PH. The on and off channels of the visual system. In: Cohen B, Bodis-Wollner I, eds. Vision and the brain. The organization of the central visual system. New York: Raven Press, 1990: 35-41.

18 Lennie P. Parallel visual pathways: a review. Vision Res 1980 20: 561-94.

19 Rea MS, Oulette MJ. Visual performance using reaction times. Lighting Res Technol 1988; 20: 139-53.

20 White TW, Irwin GE, Williams M. Asymmetry in the 
brightness and darkness Broca-Sulzer effects. Vision Res 1980; 20: 723-6.

21 Shechter S, Hochstein S. On and off pathway contributions to apparent motion perception. Vision Res 1990; 30: to apparent

22 Mutlukan E, Damato BE. The dark perimetric stimulus. $\mathrm{Br} \mathcal{F}$ Ophthalmol 1992; 76: 264-7.

23 Wehrhahn C, Rapf D. ON- and OFF-pathways form separate neural substrates for motion perception: psychophysical evidence. F Neurosci 1992; 12: 2247-50.

24 Mutlukan E, Bradnam M, Keating D, Damato BE. Visual evoked cortical potentials from transient dark and bright stimuli: selective 'on' and 'off pathway testing? Doc Ophthalmol 1992; 80: 171-81.

25 Zemon V, Gordon J, Welch J. Asymmetries in on and off visual pathways of humans revealed using contrast evoked cortical potentials. Visual Neuro-sci 1988; 1: 145-50.

26 Gouras $P$, Zrenner E. Color coding in primate retina. Vision Res 1981; 21: 1591-8.

27 Zrenner E. Neurophysiological aspects of colour mechanisms in the primate retina. In: Mollon J, Sharpe LT, eds. Color vision: physiology and psychophysics. New York: Academic vision: physiology and

28 Purpura K, Kaplan E, Shapley RM. Background light and the contrast gain of primate $P$ and $M$ retinal ganglion cells. Proc Natl Acad Sci USA 1988; 85: 4534-7.

29 Brannan JR, Bodis-Wollner I. Evidence for two system mediating perceived contrast. Vis Neurosci 1991; 6: 587-92.

30 Merigan WH. Chromatic and achromatic vision of macaques: role of the $P$ pathway. $\mathcal{F}$ Neurosci $1989 ; 9: 776-83$.

31 Lee BB, Pokorny J, Smith VC, Martin PR, Valberg A. Luminance and chromatic modulation sensitivity of macaque ganglion cells and human observers. $\mathcal{F} \mathrm{Opt} \mathrm{Soc} \mathrm{Am}$ macaque ganglion

32 Lennie P. Parallel visual pathways: a review. Vision Res 1980; 20: 561-94.

33 Bassi CJ, Lehmkuhle S. Clinical implications of parallel visual pathways. F Am Optom Assoc 1990; 61: 98-110.

34 Asai T, Katsumori N, Mizokami K. Retinal ganglion cell damage in human glaucoma: 1 . Studies on somal diameter. Folia Ophthalmol f pn 1987; 38: 701-9.

35 Asai T, Katsumori N, Mizokami K. Retinal ganglion cell damage in human glaucoma: 2 . Studies on damage pattern. Acta Soc Ophthalmol Y pn 1987; 91: 1204-13.

36 Quigley HA, Sanchez RM, Dunkelberger GR, L'Hernault NL, Baginski TA. Chronic glaucoma selectively damages large optic nerve fibers. Invest Ophthalmol Vis Sci 1987; 28: 913-20.

37 Mutlukan E. Perimetry with dark stimulus and testing offcentre ganglion cells in glaucoma. Dr Mary Hawthorne
research essay in medical ophthalmology. University of research essay in medical ophtha

38 Mutlukan E. Computerised off-pathway testing: the dark stimulus in diagnosis of visual dysfunction. Presented at the Symposium on Ophthalmological Image Processing. The Rank Prize Funds, England, 1992.

39 Highman VN. Examination of the central visual field at a reading distance. $\mathrm{Br} F$ Ophthalmol 1968; 52: 408-14.

40 Pitts Crick R, Pitts Crick JC. Apparatus for detecting visual field defects of the eye. UK Patent Application. GB 2031607 A. UK Patent Office Publication, London, 1978.

41 Elenius V. Rod saturation permetry; testing the cone function with achromatic objects. Arch Ophthalmol 1985; 103: 51923 .
42 Damato BE. Oculokinetic perimetry: a simple visual field test for use in the community. $\mathrm{Br} \mathcal{F}$ Ophthalmol 1985; 69: 927-31.

43 Mutlukan E, Cullen JF. Perimetry apparatus for the examination of central visual field. UK Patent Application. GB2264366A. UK Patent Office Publications, London, 1993.

44 Brunsmann J, Brunsmann F, Krastel H. Prototyp eines programmgesteuerten Video-Kampimeters. Fortschr Ophthalmol 1985; 82: 578-80.

45 Krastel H, Meyer Josten C, Brunsmann J, Brunsmann F Hochauflosende kontrolle des zentralen gesichtfeldes mit dem videokampimeter. Fortschr Ophthalmol 1988; 85: $750-5$.

46 Regan D, Milner BA, Heron JR. Delayed visual perception and delayed visual evoked potentials in the spinal form of multiple sclerosis and in retrobulbar neuritis. Brain 1976; 99: 43-66.

47 Mutlukan E, Keating D, Damato BE. A touch-screen multistimulus video campimeter. In: Mills R, ed. Perimetry update 92/93. New York, Amstelveen: Kugler-Ghedini, 1993: 589-95.

48 Mutlukan E, Damato BE, McFadzean R, McGarvie J, Evans A. CAMEC in Neuro-Ophthalmology. Presented at the IXth International Neuro-Ophthalmology Symposium Williamsburg, Virginia, USA, 1992.

49 Johnston SC, Damato BE, Evans AL, Allan D. Computerised visual field test for children using multiple moving fixation targets. Med Biol Eng Comput 1989; 27: 612-6.

50 Westheimer G. The oscilloscopic view: retinal illuminance and contrast of point and line targets. Vision Res 1985; 25: 1097-2003.

51 Horowitz $P$, Winfield $H$. The art of electronics. Cambridge: Cambridge University Press, 1982: 14

52 STATPAC User's Guide. San Leandro, California: AllerganHumphrey, 1987.

53 Aulhorn E, Karmeyer H. Frequency distribution in early glaucomatous visual field defects. Doc Ophthalmol Proc Ser 1977; 14: 75-83.

54 Flammer J, Drance SM, Augustiny L, Funkhouser A. Quantification of visual field defects with automated perimetry. Invest Ophthalmol Vis Sci 1985; 26: 176-81.

55 Heiil A, Lindgren G, Olsson J, Asman P. Visual field interpretation with empiric probability maps. Arch Ophthalmol 1989; 107: 204-8.

56 Caprioli J. Automated perimetry in glaucoma. In: Walsh T, ed. Visual fields, examination and interpretation. San Francisco: American Academy of Ophthalmology, 1990.

57 Drance SM. Diffuse visual field loss in open-angle glaucoma. Ophthalmology 1991; 98: 1533-8.

58 Langerhorst CT, van den Berg TJTP, Greve EL. Is there general reduction of sensitivity in glaucoma? Int Ophthalmol 1989; 13: 31-5.

59 Mutlukan E, Damato BE. Visibility threshold for dark perimetric stimulus. In: Mills R, ed. Perimetry update 92/93. New York, Amstelveen: Kugler \& Ghedini, 1993: 345-51.

60 Heijl A, Lindgren A, Lindgren G. Test-retest variability in glaucomatous visual fields. Am $\mathcal{F}$ Ophthalmol 1989; 108: glauc-5.

61 Mutlukan E. Glaucomatous optic neuropathy causes sensitivity loss to light offsets in the visual field. Neuroreport 1993 ; 4: 1159-62. 